\title{
ANALYSIS OF RIVER FLOW DATA TO DEVELOP STAGE-DISCHARGE RELATIONSHIP
}

\author{
Jinet Das ${ }^{1}$, Akshay Chaudhary ${ }^{2}$ \\ ${ }^{1,2}$ M.E Student, Irrigation and Hydraulics Department, PEC University of Technology, Chandigarh, India
}

\begin{abstract}
For investigation and design of river valley projects, assessment of the water resources potential of river basins and peak discharge is to be made. For these, the collection of daily discharge data is necessary. But direct measurement of daily discharge in a number of points in all streams is not only prohibitive in cost, but also very much time consuming, which can be best achieved by using stagedischarge relationship.

In the present work, field data of three gauging sites, i.e. Theni (Basin: Mahanadi to Kanyakumari), Pingalwada (Basin: Mahi, Sabarmati and others) and Ghatsila (Basin: Subarnarekha, Burhabalang \& Baitarni) were analysed to develop the steady-state stagedischarge relationship. Stage and Discharge data with the time of the gauging stations were available. Erroneous values were identified by comparative examination of the stage-hydrograph and discharge-hydrograph plotted one above the other. These values were rectified before developing stage-discharge equations.
\end{abstract}

Keywords: Basins, Discharge, Gauge, Hydrograph, Rating curve and Stage.

\section{INTRODUCTION}

For investigation and design of river valley projects, assessment of the water resources potential of river basins and peak discharge is to be made. For these, the collection of daily discharge data is necessary. After a number of discharge measurements made at a gauging station with simultaneous stage observations the results are plotted on a graph paper. The plot between the discharge and the stage of the river is referred to as "Stage-Discharge relation" or "Rating curve". This curve further helps us to calculate the discharge by simply reading the gauge and finding out the corresponding discharge.

Measurement of discharge by this method involves a two-step procedure. The development of the stage - discharge relationship forms the first step and is of utmost importance. Once the stage-discharge relationship is established, the subsequent procedure consists of measuring the stage and obtaining the discharge corresponding to the stage from the stage-discharge relationship [1]. Collection of stage data is very simple and a continuous data can be obtained through automatic stage recorders at a low cost. The steady-state relationship provided by the rating curve is expressed by the equation given below:

$$
Q=C\left(G-G_{0}\right)^{n}
$$

Where,

Q = Stream discharge (steady-state)

G = Gauge height
$\mathbf{G}_{\mathbf{0}} \quad=$ Gauge height corresponding to zero discharge

$\mathbf{C}$ and $\mathbf{n}$ are rating curve constant

Using the field data, the values of $\mathbf{C}$ and $\mathbf{n}$ for the gauging stations were determined, applying least square principle and the value of $\mathbf{G}_{\mathbf{0}}$ was obtained by a form of optimization through trials. The efficiency of the fitted curve and the minimum number of observations necessary for establishing a reliable stage-discharge relationship were used to indicate the reliability of the developed equation. Necessary computer programs were developed. Before analyzing the field data, the computer program developed was tested with three sets of stage-discharge data for which the stage-discharge relationships were known.

The continuous records of discharge at gauging stations were computed by applying a discharge rating to the stage data. The discharge rating curve transforms the continuous stage data to a continuous record of stream discharge, but it is simultaneously used to transform model forecasted flow hydrographs into stage hydrographs. This is required, for instance, to estimate the inundated areas during a flood [1]. Rating curves may be simple or complex depending on the river reach and flow regime. These relations are typically developed empirically from periodic measurements of stage and discharge. The data obtained from the measurements are plotted against the concurrent stage to define the rating curve for the stream. For new gauging stations, many discharge measurements are required to develop the stage discharge relation throughout the entire range of stream flow data. The 
ISO regulation 1100-2(ISO, 1998) recommends atleast 12-15 discharge measurements during the period of analysis [2,3]. Thus, the rating curve is a very important tool in surface hydrology because the reliability of discharge data values is highly dependent on a satisfactory stage-discharge relationship at the gauging station. In rating curve, the discharge is plotted along the abscissa and the stage along the ordinate. It is prepared from discharge measurements taken at various stages over the range to be covered by the curve. Although the preparation of rating curves seems to be an essentially empiric task, a wide theoretical background is needed to create a reliable tool to switch from measured water height to discharge. The rating curve has been and is currently an extensively used tool in hydrology to estimate discharge in natural and/or artificial open channel.

\section{METHODOLOGY AND ANALYSIS}

\subsection{Method Adopted for the Determination of the}

\section{Constants $\left(\mathbf{C}, \mathbf{n}\right.$ and $\left.\mathbf{G}_{\mathbf{0}}\right)$}

As pointed out earlier, the stage-discharge observations at a gauging site may be fitted by a curve given by equation (1). If the value of $\mathbf{G}_{\mathbf{0}}$ is known the value of $\mathbf{C}$ and $\mathbf{n}$ for the best fit curve to a number of observations of stage and discharge can be obtained by the least square error method. Taking logarithm of equation (1) we get,

$$
\log Q=n \log \left(G-G_{0}\right)+\log
$$

This can be written as,

$$
\mathbf{y}=\mathbf{A} \cdot \mathbf{x}+\mathbf{B}
$$

In which,

$\mathrm{y}=\log \mathrm{Q}$

$\mathrm{X}=\log \left(\mathrm{G}-\mathrm{G}_{\mathrm{o}}\right)$

$\mathrm{A}=\mathrm{n}$

$\mathrm{B}=\log \mathrm{C}$, i.e. $\mathrm{C}=(10) \mathrm{B}$

For $\mathrm{N}$ set of observations of stage and discharge (i.e. $\mathbf{G} \boldsymbol{\&} \mathbf{Q}$ ) and known value of $\mathbf{G}_{\mathbf{0}}$ the least square principle yields,

$$
A=\frac{\Sigma x y-(\Sigma x \Sigma y) / N}{\left(\Sigma x^{2}\right)-(\Sigma x)^{2} / N} \quad \& B=\frac{(\Sigma y-A \cdot \Sigma x)}{N}
$$

The value of $\mathbf{A}$ and $\mathbf{B}$ so obtained can be used to compute $\mathbf{n} \& \mathbf{C}$. But to get the values of $\mathbf{A}$ and $\mathbf{B}$ it would be necessary to determine $\mathbf{G}_{\mathbf{0}}$. For this a form of optimization through trials were used. An initial guess value of $\mathbf{G}_{\mathbf{o}}$, which was lower than the minimum observed value of the stage were used. The corresponding values on $\mathbf{n}$ and $\mathbf{C}$ were obtained after optimization of $\mathbf{G}_{\mathbf{0}}$. From the computed values of $\mathbf{n}$ and $\mathbf{C}$, the sum of the squared deviation (i.e. $\Sigma$ $\left.\left(Q_{\text {observed }}-\mathrm{Q}_{\text {computed }}\right)^{2}\right)$ was calculated [4]. With the stipulated increment in the value of $\mathbf{G}_{\mathbf{o}}$, the next trial value was taken and the computation procedures were repeated to get the value of the sum of the squared deviations for the same. In this way the value of $\mathbf{G}_{\mathbf{o}}$ was increased in steps upto the observed minimum value of the stage. The best value of $\mathbf{G}_{\mathbf{0}}$ and the corresponding values of $\mathbf{n}$ and $\mathbf{C}$ obtained were those at which the sum of the squared deviations was minimized.

\subsection{Testing the Goodness of Fit}

Determination of the values of $\mathbf{G}_{\mathbf{0}}, \mathbf{C}$ and $\mathbf{n}$ establishes the mathematical relationship between the discharge and stage that should hold good for a gauging station. But the question as to how well this derived relationship fits in with the observed data needs to be tested. A relationship to check the goodness of fit is as follows:

$$
\mathbf{n}=\frac{\alpha^{2}-\beta^{2}}{\alpha^{2}} * 100 \%
$$

Where, $\boldsymbol{\alpha}^{2}=\Sigma\left(\mathrm{Q}_{\mathrm{o}}-\mathrm{Q}\right)^{2} / \mathrm{N}, \boldsymbol{\beta}^{2}=\Sigma\left(\mathrm{Q}_{\mathrm{o}}-\mathrm{Q}_{\mathrm{c}}\right)^{2} / \mathrm{N}$

$\mathbf{Q}_{\mathbf{o}}$ and $\mathbf{Q}_{\mathbf{c}}$ are the observed and computed values of discharge and $\mathbf{Q}$ is the average value of $\mathbf{N}$ number of observed discharges.

For the best fit, value of $\mathbf{n}$ should be around $80 \%$.

\subsection{Number of Observations Necessary for} Establishing a Reliable Stage-Discharge Relationship

It has been reported that for developing the stagedischarge relationship with any degree of reliability, there should be sufficient number of observations, suitably distributed throughout the whole range of stage.

Due to errors of measurement and various other factors, it is not unusual for individual points to vary by $20 \%$ or more from the mean stage-discharge relationship. The greater the width of scatter band, greater should be the number of observations necessary to ensure that the mean relationship is determined with an acceptable degree of reliability [4]. At a confidence level of 20 to 1 (i.e. 80\%), the minimum number of observations necessary (m) is given by:

$$
\mathbf{m}=\left(Z \cdot S_{D} / P\right)^{2}
$$

Where, $\mathbf{Z}=1.28$ at $80 \%$ confidence limit, $\mathbf{S}_{\mathbf{D}}$ is the standard deviation of the observed data and $\mathbf{P}$ is the margin of error (in percentage) whose value is taken as 
$5 \%$.

\subsection{Development of Steady-Stage Stage-Discharge}

\section{Relationship from the Analysis of River Data}

From the observed river data, the actual rating curves were developed through the following steps:

\subsubsection{Adjustment of Faulty Observations By}

\section{Comparative Examination}

Incorrect or faulty values may come into record due to instrumental, computational or copying errors. A comparative examination of the observed stage hydrograph and the discharge hydrograph plotted one above the other helps in detecting the faulty values. The observed faulty values were adjusted by shifting them upwards or downwards to bring them into conformity with the general trend of the hydrographs.

- For THENI, the total number of faulty values identified was 2, out of which 1 were in stage-data and 1 in discharge-data. These data were rectified.

- For PINGALWADA, the total number of faulty values identified was 4 , out of which 2 were in stage-data and 2 in discharge-data. These data were rectified.

- For GHATSILA, the total number of faulty values identified was 4 , out of which 2 were in stage-data and 2 in discharge-data. These data were rectified.

\subsubsection{Fitting of the Trial Curve for Steady Flow Data}

For the purpose of pruning out spurious data to secure homogeneous data for correct stage-discharge relationship, trial curve is drawn. Generally, separate curves are drawn through the points of rising and falling stages. If it is not possible to draw separate curves, then one curve is drawn. The trail curve should satisfy the goodness of fit criteria [5].

- For THENI, the total number of steady-state data was 33 out of which only 9 were for the rising stage. So no attempt was made to treat the rising stage and falling stage separately. Using all the data together the equation of the trial curve was computed as:

$$
Q=16.14(G-6.54)^{2.211}
$$

The efficiency calculated was $99.07 \%$ indicating that the fitted curve satisfied the goodness of fit criteria.

- For PINGALWADA, the total number of steady-state data was 22 out of which only 6 were for the rising stage. So no attempt was made to treat the rising stage and falling stage separately. Using all the data together the equation of the trial curve was computed as:

$$
Q=10.74(G-20.16)^{1.730}
$$

The efficiency calculated was $88.21 \%$ indicating that the fitted curve satisfied the goodness of fit criteria.

- For GHATSILA, the total number of steady-state data was 41 out of which only 8 were for the rising stage. So no attempt was made to treat the rising stage and falling stage separately. Using all the data together the equation of the trial curve was computed as:

$$
Q=97.73(G-15.71){ }^{1.970}
$$

The efficiency calculated was $87.12 \%$ indicating that the fitted curve satisfied the goodness of fit criteria.

\subsubsection{Pruning Out of Observation Values to Secure Homogeneous Data}

The observations obtained very far away from the trial curve should be pruned out to secure homogeneous data for correct stage-discharge relationship. The data whose percent deviation was more than $20 \%$ in discharge was pruned out.

Number of data rejected

- $\quad$ For THENI -5 out of 33

- For PINGALWADA - 2 out of 22

- For GHATSILA -8 out of 41

\subsubsection{Development of Actual Rating Curve and its Reliability Test}

After obtaining the homogeneous data, actual rating curve was drawn through these points. The actual rating curve is said to be reliable if the minimum number of observations necessary for establishing a reliable stage-discharge relationship as given by equation (5) is less than or equal to the number of observed homogeneous data through which the actual curve is drawn [5].

- For THENI, the actual rating curve was given by the equation:

$$
Q=16.509(G-6.54)^{2.183}
$$

And the efficiency calculated was $99.8 \%$, indicating that the actual curve satisfied the goodness of fit criteria.

- For PINGALWADA, the actual rating curve was given by the equation:

$$
Q=8.78(G-19.98){ }^{1.818}
$$


And the efficiency calculated was $90.17 \%$, indicating that the actual curve satisfied the goodness of fit criteria.

- For GHATSILA, the actual rating curve was given by the equation:

$$
Q=63.40(G-15.43)^{2.166}
$$

And the efficiency calculated was $89.64 \%$, indicating that the actual curve satisfied the goodness of fit criteria.

\section{RESULTS AND DISCUSSION}

\subsection{For THENI River Basin, the Actual Rating Curve}

\section{was given by the Equation (9).}

Though the data were well fitted with the developed curve, the minimum number of observations necessary was 28, which was less than the number of available homogeneous data. So the fitted relationship developed is reliable. The stage discharge relation for Theni River is depicted below in figure 1 .

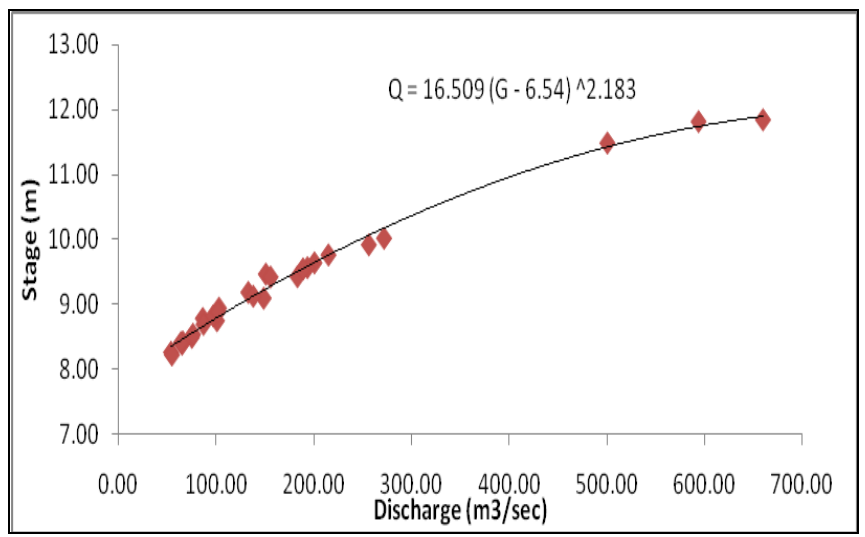

Fig.1: Rating curve of THENI (1980-2012)

\subsection{For PINGALWADA River Basin, the Actual}

\section{Rating Curve was given by the Equation (10).}

Though the data were well fitted with the developed curve, the minimum number of observations necessary was 20 , which was less than the number of available homogeneous data. So the fitted relationship developed is reliable. The stage discharge relation for Pingalwada River is depicted below in figure 2 .

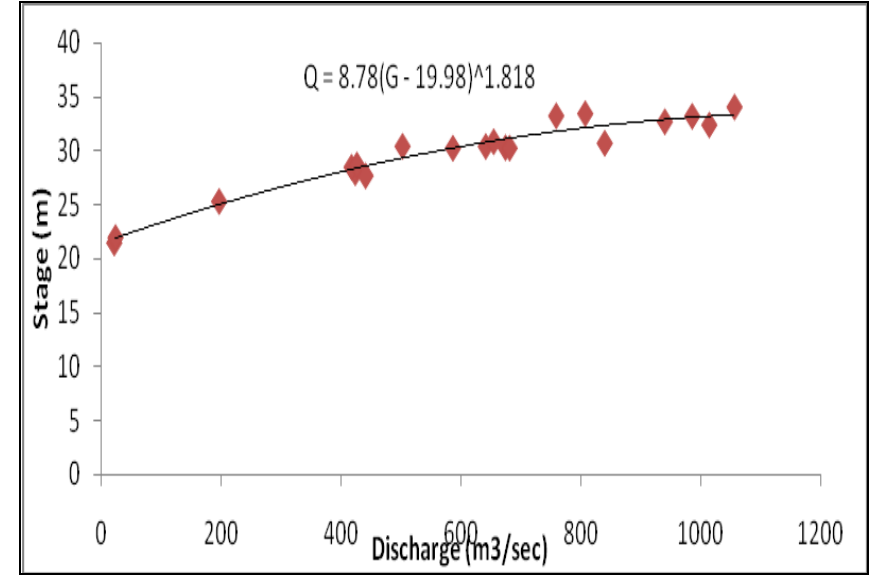

Fig.2: Rating curve of PINGALWADA (1990-2011)

\subsection{For GHATSILA River Basin, the Actual Rating Curve was given by the Equation (11).}

Though the data were well fitted with the developed curve, the minimum number of observations necessary was 33, which was less than the number of available homogeneous data. So the fitted relationship developed is reliable. The stage discharge relation for Ghatsila River is depicted below in figure 3 .

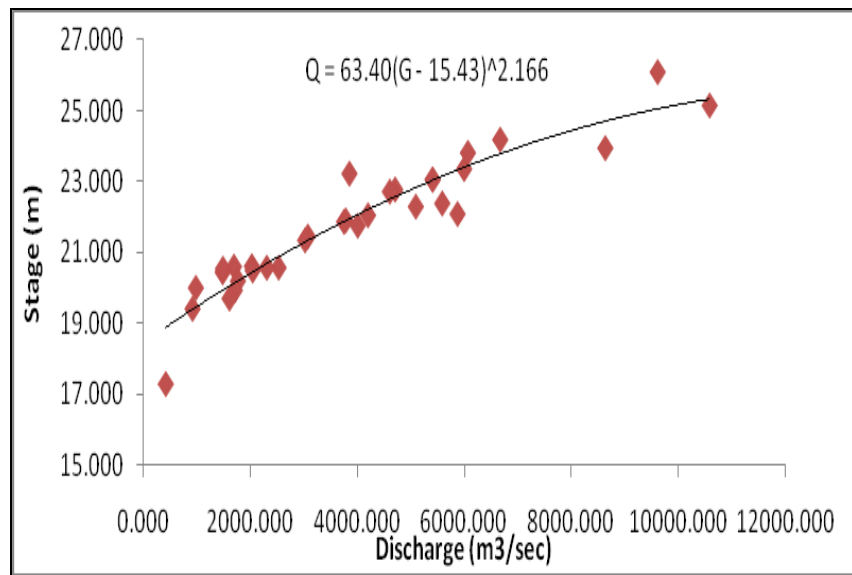

Fig.3: Rating curve of GHATSILA (1972-2012)

\section{CONCLUSIONS}

The observations made from the study suggested that systematic and continuous discharge data is not actually observed; instead its records are made from converting the water level data to discharge by using a stage-discharge relationship.

Thus, based upon the obtained results from the study, we concluded that,

1) The zero discharge in the stream " $G_{0}$ " is a hypothetical value that cannot be measured in the field. 
2) The rating equations developed are:

- For THENI, $Q=16.509(G-6.54)^{2.183}$

- For PINGALWADA, $Q=8.78(G-19.98)^{1.818}$

- For GHATSILA, $Q=63.40(G-15.43)^{2.166}$

\section{REFERENCES}

[1] Stream gauging by M.G. Hiranandani and S.V. Chitle, Central water and Power Research Station, Poona.

[2] ISO 1100-1, 1996, Measurement of liquid flow in open channels - Part 1: Establishment and operation of a gauging station.

[3] ISO 1100-2, 1998, Measurement of liquid flow in open channels - Part 2: Determination of the stage-discharge relation.

[4] Applied Hydrology by K.N. Mutreja, Tata McGrawHill, New Delhi.

[5] A Text Book of Hydrology by Dr. P.Jaya Rami Reddy, Laxmi Publications, Delhi.

\section{BIOGRAPHIES}

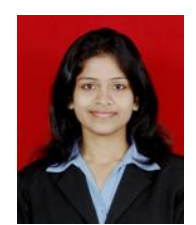

Jinet Das has completed her B.Tech in Civil Engineering from Gautam Budhh Technical University and is currently pursuing M.E in Irrigation \& Hydraulics Engineering from PEC University of Technology. Her main interests include water resources planning \& management and advanced hydrology.

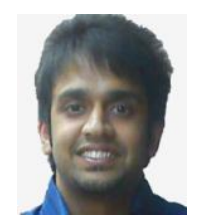

Akshay Chaudhary has completed his B.Tech in Civil Engineering from Jaypee university of Information Technology, Solan and is currently pursuing M.E in Irrigation \& Hydraulics Engineering from PEC University of Technology. His main interests include open channel flow and designing. 